\title{
Analysis on Characteristics, Motivations and Opportunities of Multinational Mergers and Acquisitions of Chinese Equipment Manufacturing Industry
}

\author{
Xiaorui He* \\ School of management, Shanghai University, Shanghai, China. \\ *xiaoruimj@163.com
}

Keywords: Equipment manufacturing enterprises; characteristics of multinational MAs; motivations of multinational MAs; opportunities.

\begin{abstract}
As a national strategic support industry, multinational mergers and acquisitions (MAs) activities of equipment manufacturing industry deserve a special academic research. This paper uses 211 samples to analyze the characteristics, motivations and opportunities of multinational M\&As by Chinese equipment manufacturing enterprises. The characteristics are as follows: 1 . PE has become an important partner for multinational acquisitions by equipment manufacturing enterprises; 2 . after 2013, multinational M\&As in Israel, Korea, and Singapore began to become active; 3. multinational MAs activities in the medical device industry have developed rapidly. As for the motivation of MAs, international innovation resources are the most important factor driving Chinese equipment manufacturing enterprises' multinational mergers and acquisitions. In the future, with the active cooperation of domestic "One Belt and One Road" and "supply-side reform" strategies, Chinese equipment manufacturing industry will usher in more opportunities.
\end{abstract}

\section{Introduction}

Equipment manufacturing industry is the main battlefield of science and technology innovation in a country and an important part of the country's core competitiveness. Since the financial crisis, Chinese equipment manufacturing enterprises have achieved rapid development of their huge domestic market, abundant capital and abundant human resources. At present, the total output value of Chinese equipment manufacturing industry has leapt to the top in the world. However, due to the lack of core technologies and key equipment, Chinese equipment manufacturing industry has always been in a "big but not strong" state. To realize the transformation from Chinese manufacturing to Chinese creating, we must enhance the ability of independent innovation.

\section{The Time Process And the New Period Characteristics of Multinational M\&As of Chinese Equipment Manufacturing Industry}

\subsection{Data Sources and Industry Segmentation Standards.}

The sample data used in this study comes from the Zero2IPO Research Center and listed enterprises' annual report information. The sample data spans from 2001 to August 2016, Chinese equipment manufacturing enterprises have occupied 211 multinational mergers and acquisitions. Industry segmentation standards is based on the national economic industry classification and code (GB/T4754-2002).

\subsection{M\&As Time Process of Chinese Equipment Manufacturing Industry.}

The multinational M\&As of Chinese equipment manufacturing enterprises rose in 2001 (Figure 1) and can be roughly divided into three phases. The first phase (starting phase from 2001 to 2007): There are fewer mergers and acquisitions at this stage, and the transaction amount is basically not announced; the second phase (high-speed development phase in 2008-2013): the number and amount of multinational M\&As achieve rapid growth, the number of cases has increased 10 times in 6 years, and the transaction amount has increased by 6.46 times. In the third phase (after 2014), under the 
premise that the number of mergers and acquisitions remains relatively stable, the total amount of transactions has grown rapidly, and multinational acquisitions have become larger.

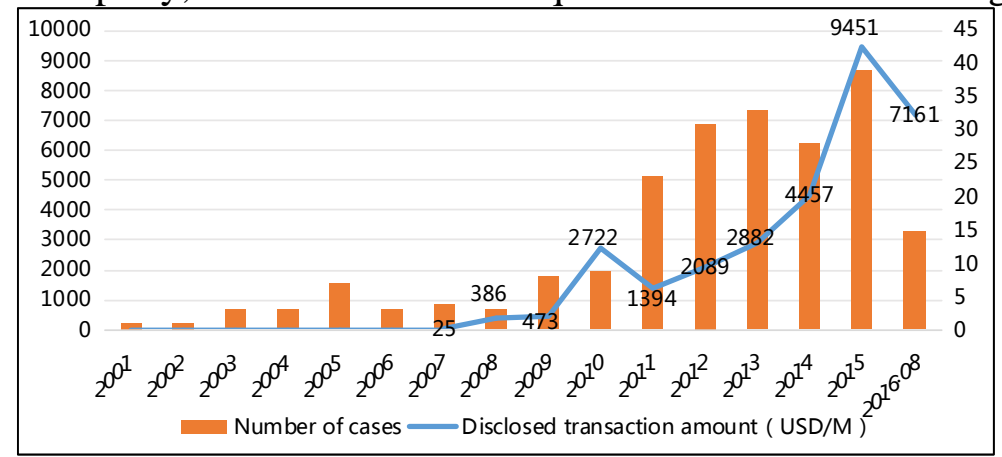

Figure 1. M\&A time process of Chinese equipment manufacturing industry

From 2001 to 2007, the multinational M\&As of Chinese equipment manufacturing industry was still in its infancy. The sponsors of MAs are mainly state-owned enterprises, relied in the advantage of market and capital, enterprises introduced overseas advanced technologies; about the acquisition targets, they mainly acquire foreign enterprise that is in recession or on the brink of bankruptcy.

From 2008 to 2013, multinational M\&As of Chinese equipment manufacturing industry developed rapidly. The adjustment of the global equipment manufacturing pattern brought by the financial crisis and the global economic recession has provided the opportunity for Chinese equipment manufacturing enterprises to relocate themselves in the role of international labor division. Enterprises selected enterprises with advanced technologies or merged with enterprises that had higher matching degree with existing enterprises to acquire original technologies of the targets.

After 2014, the equipment manufacturing industry is facing the pressure of industrial upgrading, and multinational MAs activities are shifting to the high-end of the industry chain. Marine equipment, high-end medical equipment, smart grid equipment and other high-end equipment industry are the focus of multinational MAs; as for the acquisition target, they choose to acquire industry leading enterprises that have a good reputation in foreign countries and possess important core technologies.

2.3 Analysis on New Period Characteristics of Multinational M\&A by Chinese Equipment Manufacturing Industry.

\subsection{PE Becomes an Important Partner in Multinational M\&As.}

From 2008 to August 2016, there were 187 multinational M\&As in Chinese equipment manufacturing industry, and 68 cases were supported by PE; since 2010, the number of mergers and acquisitions cases supported by PE has increased rapidly, and the proportion has also increased, the breakthroughs in 2015 accounted for $50 \%$ of the total. The 2008 financial crisis provided an excellent opportunity for multinational acquisitions of Chinese equipment manufacturing enterprises. However, due to the general lack of multinational MAs experience, Chinese enterprises do not know how to avoid the "reefs" they may encounter. The powerful PE follows the trend of history. In addition to providing financial support, $\mathrm{PE}$ often has more efficient information channels, a better international perspective, and more overseas investment experience. It can make up for the lack of overseas MAs experience and management of Chinese enterprises, allowing enterprises to better grasp overseas development opportunities.

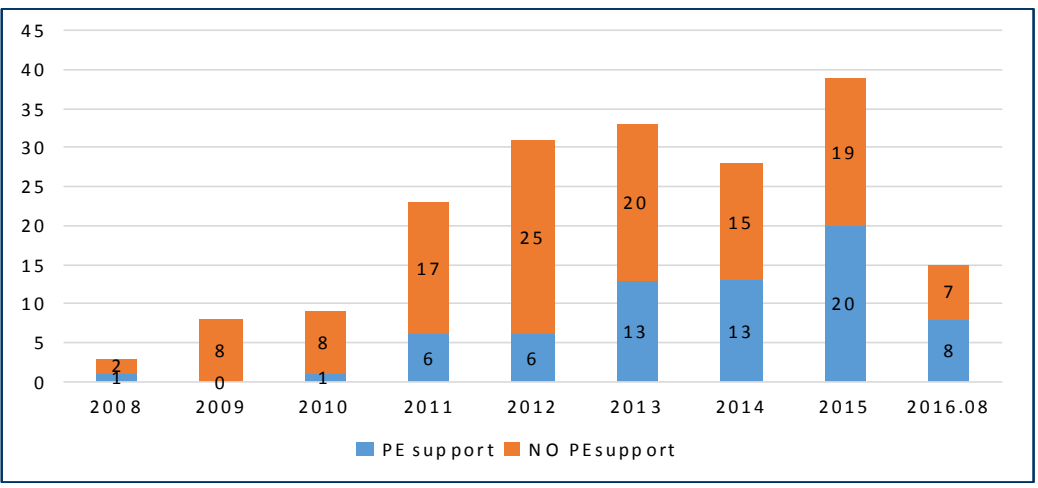

Figure 2 .PE participation in multinational acquisitions of Chinese equipment manufacturers 


\subsubsection{Israel, Singapore and South Korea are the New Battlefields for M\&As in Chinese Enterprises.}

From the perspective of regional distribution, the target countries for overseas acquisitions by Chinese equipment manufacturing enterprises are mainly concentrated in Western Europe and North America, while Israel, Singapore, and South Korea are the new battlefields for Chinese enterprises' M\&As (Table 1). The major destinations for overseas acquisitions of Chinese equipment manufacturing enterprises are Germany and the United States. Although Japan has a very mature and well-developed machinery and equipment industry, due to historical reasons and the tight political relations between China and Japan, Japanese enterprises are not willing to sell. After 2013, Chinese equipment manufacturing enterprises started active mergers and acquisitions in Israel, Singapore, and South Korea.

Table 1 Distribution of multinational M\&A Locations of Chinese Equipment Manufacturing Enterprises

\begin{tabular}{|c|c|c|c|c|c|c|c|c|c|c|}
\hline & 2008 & 2009 & 2010 & 2011 & 2012 & 2013 & 2014 & 2015 & 2016 & Total \\
\hline Israel & & & & & & 1 & 1 & 3 & & 5 \\
\hline Singapore & & & & & & 1 & 2 & 1 & & 4 \\
\hline South Korea & & & & & & & & 2 & & 2 \\
\hline Germany & & & 1 & 6 & 13 & 9 & 9 & 6 & 5 & 49 \\
\hline United States & 1 & 2 & 5 & 3 & 3 & 7 & 4 & 10 & 4 & 39 \\
\hline Italy & 1 & & & 4 & 3 & 2 & 2 & 6 & 1 & 19 \\
\hline France & 1 & 1 & & 2 & & 1 & 2 & 1 & 1 & 9 \\
\hline Canada & & & 1 & 1 & 3 & 1 & 1 & 1 & & 8 \\
\hline Sweden & & 1 & 1 & 1 & 1 & 1 & & 2 & & 7 \\
\hline $\begin{array}{l}\text { United } \\
\text { Kingdom }\end{array}$ & & & 1 & & & 2 & 2 & 1 & 1 & 7 \\
\hline Netherlands & & & & 1 & 4 & & 1 & & & 6 \\
\hline Austria & & 1 & & 1 & & & 2 & 1 & & 5 \\
\hline Japan & & 2 & & 1 & 2 & & & & & 5 \\
\hline Australia & & 1 & & 1 & & 1 & 1 & & & 4 \\
\hline Poland & & & & & 1 & 2 & & & & 3 \\
\hline Switzerland & & & & 1 & & 1 & 1 & & & 3 \\
\hline Belgium & & & & & & 1 & & & 1 & 2 \\
\hline Russia & & & & & 1 & & & & & 1 \\
\hline Czech & & & & & & & & 1 & & 1 \\
\hline Luxembourg & & & & & & 1 & & & & 1 \\
\hline Spain & & & & & & 1 & & & & 1 \\
\hline India & & & & & & 1 & & & & 1 \\
\hline $\begin{array}{r}\text { Other } \\
\text { countries }\end{array}$ & & & & 1 & & & & 1 & 2 & 4 \\
\hline Total & 3 & 8 & 9 & 23 & 31 & 33 & 28 & 36 & 15 & 186 \\
\hline
\end{tabular}

Israel is one of the world's leading centers for the development of innovative medical devices, there are nearly 300 medical device enterprises, and the vast majority are emerging enterprises in the early stages of development. In recent years, Israel's medical device industry has attracted a large amount of Chinese investors. It made Israel the most active target for MAs activities of Chinese medical equipment enterprises besides the United States.

As one of the first countries to take off in the Asian economy, Singapore is the world's largest producer of self-elevation oil drilling platform, it is also the second largest semiconductor production center in the world, second only to Hsinchu, Taiwan. From 2012 to 2015, the state and ministries issued a total of six important instructions, indicating that ships and marine engineering are key industries. The developed countries' policies for the protection of marine equipment have enabled China's MAs in marine equipment to focus on Singapore. 
South Korea's advanced technology in the semiconductor field is the focus of M\&As of Chinese enterprise. In the past more than 10 years, South Korean semiconductors have been holding a monopoly in the world market, and Korean enterprises now still occupy more than 70\% of the world's storage chip market. In recent years, the Chinese government has continued to increase its support for the integrated circuit (IC) industry, and local governments have also established industrial support funds to help Chinese enterprises develop IC industries and acquire foreign advanced technologies, prompting Chinese semiconductor enterprises to "walk into" Korea.

\subsubsection{Emergence of Multinational Mergers and Acquisitions in the Medical Device Industry.}

From the perspective of MAs sub-sectors (Figure 3), electrical machinery, transportation equipment and special equipment are active industries of MAs in equipment manufacturing. As the mainstream industry in the industrial field, electrical machinery will develop synchronously with the development of other industries, and its acquisitions will continue throughout. The number of transportation equipment acquisitions was the largest, mainly in the automotive-related industries, and parts and components enterprises were the main force for overseas acquisitions. At present, the key core technologies of complete vehicle parts and components are still dominated by advanced enterprises in Europe and the United States, overseas acquisitions have become the most feasible path to catch up. The MAs target in the special equipment industry has undergone a transformation from textiles and printing equipment to petrochemicals, engineering machinery, and medical devices. Compared with other sub-sectors, multinational MAs activities in the medical device industry have developed most rapidly. Starting in 2013, they have surpassed both multinational MAs number growth and quantity growth.After 2013, medical device industry occurred 13 MAs cases.

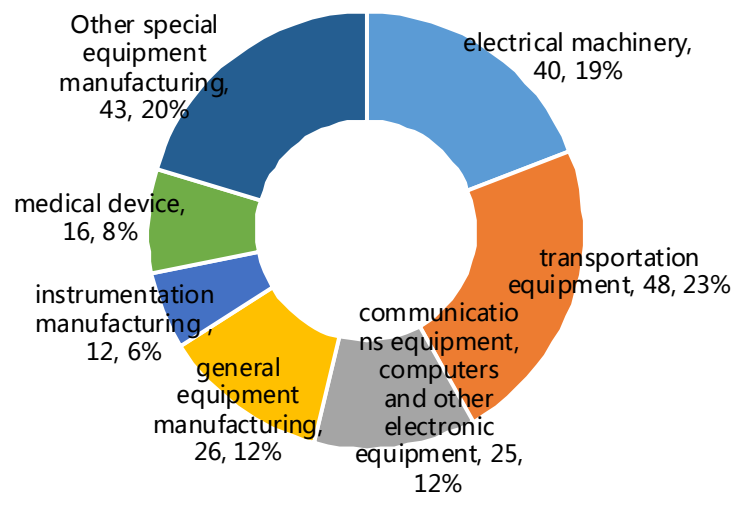

Figure 3. Number of multinational M\&A by various sub-sectors of equipment manufacturing industry

Chinese pharmaceutical enterprises have many shortcomings compared with international well-known pharmaceutical enterprises, and the gap in the field of mechanical equipment is more obvious. Multinational mass can help domestic medical device enterprises achieve technological upgrading and improvement of management levels. In the context of the continuous improvement of Chinese economic level, the domestic people's demand for medical and health care is also growing. In 2012, the Ministry of Science and Technology formulated the"12th Five-Year" special plan”for the medical device technology industry, pointing out that it will focus on supporting 10 to 15 large-scale medical device enterprise groups, the market prospects of medical instruments are clearly defined in the policy filling. As the main part of the multinational mass of medical equipment, most of the listed enterprises are listed on the GEM after 2009. After several years of digesting internal problems, the expansion will only be on the agenda. This also led to an outbreak of multinational mass of medical device enterprises after 2013. 


\section{Analysis on the Motivations of Multinational M\&As of Chinese Equipment Manufacturing Industry}

\subsection{Driving by Demand for Innovation Resources.}

Acquiring international innovation resources is the most important factor driving Chinese equipment manufacturing enterprises' multinational M\&As. Although great achievements have been made in the development of Chinese equipment manufacturing enterprises, problems such as industries"large but not strong", weak independent R\&D capabilities are prominent. In particular, high-end equipment manufacturing still has a large gap compared with foreign outstanding enterprises, which restricts the transformation and upgrading of Chinese enterprises. European Union and North America have advanced technology R\&D resources, and are the major destinations for M\&As of Chinese equipment manufacturing enterprises. After MAs, enterprises can absorb advanced technology, acquire innovative resources and interface with existing R\&D systems and technology plans to lay the foundation for building a global R\&D network, thereby enhancing independent innovation capabilities.

\subsection{Driving by Overcapacity.}

Due to the lack of core technical capabilities, Chinese equipment manufacturing industry is facing problems such as overcapacity of low-end and middle-end products, weak R\&D and industrialization capabilities, leading to further intensification of industry homogenization competition. In order to break the operational predicament, many equipment manufacturing enterprises have chosen to directly enter the international market to digest domestic excess capacity through multinational M\&As. In addition, the vicious competition brought by overcapacity will force domestic enterprises to increase their investment in innovative $R \& D$, allowing enterprises to go to international markets to acquire advanced technologies and equipment, thereby forming the relative competitive advantage of the enterprises through the upgrading of the products, so as to get out of the malignant and competitive low-lying land.

\subsection{Driving by Government Policy.}

The major national strategy and government policies at all levels are an important factor for overseas mergers and acquisitions of Chinese equipment manufacturing enterprises. Since 2015, Chinese officials have vigorously promoted international production capacity and equipment manufacturing cooperation. The State Council has successively issued "Made in China 2025" and "Guiding Opinions on Promoting International Capacity and Equipment Manufacturing Cooperation"; in coordination with The Belt and Road, FTA and other strategic deployment, Chinese equipment manufacturing enterprises have been able to go smoothly abroad. In addition, relevant departments such as the Ministry of Commerce have also issued a series of corresponding support and preferential policies to gradually improve the overseas investment management systems.

\section{Opportunities of Multinational M\&As of Chinese Equipment Manufacturing Industry}

\subsection{Convergence of Industry and Finance Accelerate, M\&As Funds Promote the Integration of} Overseas Resources.

Due to the two-way benefits of policies and markets, domestic MAs funds have developed rapidly in 2015. Represented by the "Public enterprise + PE" model, merger funds are accelerating the convergence of industrial capital and financial capital. At present, Chinese enterprises urgently need to carry out strategic transformation and industrial upgrading. The investment hot spots in the field of machinery manufacturing are also shifting from traditional industrial machinery manufacturing to high-precision manufacturing with high-tech and technological content. MAs funds can leverage their rich MAs experience and investment management capabilities at the PE end to help listed enterprises integrate strategic overseas resources required. 


\subsection{The "Belt and Road" Strategy Will Actively Promote Cooperation in Equipment Manufacturing.}

The implementation of the "Belt and Road" strategy and the promotion of international production capacity and equipment manufacturing cooperation are major strategic decisions made by the Chinese government to build a new pattern of all-round opening to the outside world. In recent years, domestic equipment manufacturing enterprises have quickly acquired foreign advanced technologies, brands, market channels and other factors through M\&A, which has led to the transformation and upgrading of domestic industries. Driven by the national "One Belt and One Road” strategy, in line with the multiple dividends of RMB internationalization and multi-level capital market construction, Chinese enterprises' overseas investment cooperation and M\&A have ushered in new opportunities.

\subsection{Supply Side Reform Promotes Multinational M\&As of Leading Enterprises.}

Extensive development methods have made Chinese equipment manufacturing industry in an awkward position with insufficient core capacity and excess production capacity. In a sense, the domestic overcapacity is structural, the structure of the industry, the quality of the industry is not high, and the unreasonable structure is the main reason. In order to solve the problem of overcapacity by improving corporate quality, high-level operators must be forced to increase industry standards. Merging and acquiring advanced manufacturing enterprises in Europe and America are the feasible ways. Leading enterprises will enjoy reform dividends in terms of capital, market and policy.

\section{Conclusions}

Chinese equipment manufacturing industry has entered a new phase of global asset allocation. It is from striving to narrow the technological gap, seeking joint technological development and accessing to overseas sales channels, to now acquiring world-leading technology, integrating competition, and quickly building global production and sales network. In the new stage, Chinese equipment manufacturing company's present more new features.At present, Chinese equipment manufacturing industry is at a critical moment in the transition from "Made in China" to "Created in China." At present, China's equipment manufacturing industry is at a critical moment in the transition from "Made in China" to "Created in China." It is an urgent need for Chinese equipment manufacturing companies to acquire international innovation resources, enhance independent innovation capability and enter the international high-end equipment manufacturing market, which will not only enhance the status of Chinese equipment manufacturing enterprises in the international labor division, but also help enterprises to get rid of domestic overcapacity. In the future, the downward pressure on the global economy will continue, and the Brexit event will continue to ferment, with the active cooperation of the "One Belt, One Road" and "supply-side reform" strategies, Chinese equipment manufacturing industry will usher in the golden time of multinational M\&As.

\section{References}

[1]. Bass an E, Chakraborty S. Resource security: Competition for global resources, strategic intent, and governments as owners [J]. Journal of International Business Studies, 2014, 45(8): 961-979.

[2]. Await S, Larsen M, and Mamba R. Accessing vs sourcing knowledge: A comparative study of $\mathrm{R} \& \mathrm{D}$ internationalization between emerging and advanced economy firms [J]. Journal of International Business Studies, 2015, 46(1): 63-86.

[3]. Wang C, Hong J, Kafouros M, et al. Exploring the role of government involvement in outward FDI from emerging economies[J]. Journal of International Business Studies, 2012, 43(7): 655-676.

[4]. Buckley P J, Yu P, Liu Q, et al. The Institutional Influence on the Location Strategies of Multinational Enterprises from Emerging Economies: Evidence from China's Cross-border Mergers and Acquisitions [J]. Management and Organization Review, 2016. 